\title{
Definindo a Arena Política Local: Sistemas Partidários Municipais na Federação Brasileira*
}

\author{
Leandro Piquet Carneiro \\ Maria Hermínia Tavares de Almeida
}

\section{INTRODUÇÃO}

$\mathrm{E}$ ste artigo trata da conexão entre a arena política local e as arenas estaduais e nacional considerando o prisma do sistema partidário. Quisemos verificar em que medida e de que forma a dinâmica político-eleitoral nos municípios é tributária do que se passa nas outras esferas da Federação.

A experiência democrática brasileira não pode ser adequadamente estudada sem se levar em conta que ela ocorre nos marcos de um sistema federativo. A Federação brasileira tem mais de cem anos e constitui uma das instituições mais relevantes para o entendimento da estruturação do sistema político brasileiro e dos processos que o movimentam. Entretanto, só recentemente se tornou objeto da atenção sistemática dos cientistas políticos. Estudos recentes têm contribuído para re-

\footnotetext{
* Este texto é um dos produtos finais da pesquisa Democracia, Política e Governo Local, projeto temático da Fundação de Amparo à Pesquisa do Estado de São Paulo - FAPESP. Em versão muito preliminar, foi discutido no seminário da área de Instituições Políticas do Departamento de Ciência Política da Universidade de São Paulo - USP. Foi apresentado também em seminário realizado no Taubman Center, da Kennedy School of Government, Harvard University, e no Kellogg Institute, University of Notre Dame. Os autores agradecem os comentários dos colegas presentes e, especialmente, as sugestões de Maria D'Alva Kinzo, Fernando Limongi, Samuel Valenzuela, Michael Coppedge e Scott Mainwaring. Agradecemos também a Ester Ribeiro o trabalho de organização dos dados e da bibliografia.
}

DADOS - Revista de Ciências Sociais, Rio de Janeiro, Vol. 51, n-2, 2008, pp. 403 a 432. 
visar teorias, formular novas hipóteses e juntar evidências sobre dimensões diversas de nossa estrutura federativa.

Em conseqüência do interesse renovado pelo tema, existe hoje um número razoável de trabalhos cujo foco não está na esfera nacional, mas sim nas instituições e nos processos políticos subnacionais, especialmente nos estados (Lima Junior, 1997; Abrucio, 1994; 1998; Abrucio e Samuels, 1997; Abrucio e Costa, 1998; Santos, 2001; Souza, 2003).

Este artigo se inscreve na perspectiva de análise do sistema político sob o prisma das esferas subnacionais; porém, seu objeto não são os estados, mas os municípios. Trata-se de um estudo exploratório. Buscamos caracterizar se e de que maneira os sistemas partidários que emergem na disputa eleitoral nos municípios se articulam e podem ser explicados pela disputa por votos nos planos estadual e nacional.

A exposição está dividida em cinco partes. Na primeira, discutimos o problema à luz da bibliografia. Na segunda, tratamos dos incentivos institucionais à independência ou, inversamente, à articulação do sistema partidário local com as demais esferas em função do marco legal que rege a política municipal. Em seguida, estabelecemos nossas hipóteses e descrevemos os dados utilizados. Na quarta parte, detalhamos suposições e o modelo de análise. Por fim, discutimos os resultados.

\section{O PROBLEMA}

Dadas as características da Federação, das regras eleitorais e daquelas que presidem a organização partidária, a articulação do sistema de partidos nas três esferas não está garantida e requer esforços de coordenação por parte das lideranças. Lavareda (1991) foi o primeiro a atentar para esse fato e a buscar evidências sobre a articulação do sistema de partidos no Brasil ao longo das instâncias federativas durante a vigência da Constituição de $1946^{1}$.

Entretanto, boa parte da literatura que tratou do tema pôs ênfase no efeito desarticulador da Federação, combinado às regras eleitorais e de organização partidária. Assim, não foram poucos os autores que, observando nosso multipartidarismo fragmentado, enfatizaram a fragilidade, a baixa institucionalização e a incoerência político-ideológica resultantes dessa peculiar combinação de instituições. Em conseqüência, o Brasil foi considerado um caso de notório subdesenvolvimento partidário (Lamounier e Meneguello, 1986). Aqui prevaleceram “par- 
tidos do tipo catch-all, descentralizados, comparativamente indisciplinados e comparativamente individualistas" (Mainwaring, 1999:5). A arregimentação dos políticos estaria determinada mais por considerações relacionadas à política estadual ou local do que por clivagens nacionais. A importância das carreiras nos níveis subnacionais (Samuels, 1998; Mainwaring, 1999) contribuiria, de certa forma, não só para a existência de um multipartidarismo fragmentado ao extremo como também para sua falta de inteligibilidade político-ideológica ${ }^{2}$.

A literatura especializada tem razão quando afirma o caráter descentralizado do sistema de partidos, a importância da disputa política no nível subnacional e, especialmente, a contenda eleitoral nos estados para a definição de suas feições. Contudo, dessas características não se pode inferir que haja desconexão entre os diferentes níveis do sistema, muito menos que sua base - a esfera municipal - seja sempre moldada de forma idiossincrática pelas disputas locais.

Nosso propósito é, pois, verificar como, em que medida e em que condições o sistema partidário que resulta das eleições municipais se articula com aquele produzido pelas disputas estaduais e nacional.

Desde a publicação de Making Votes Count (Cox, 1997), sabemos que a organização de um sistema partidário nacional envolve sempre diferentes problemas de coordenação e que resultados eleitorais dependem tanto de instituições quanto de estratégias dos atores políticos. $\mathrm{O}$ suposto teórico é que os eleitores votam de forma instrumental, ou seja, calculam a probabilidade de que suas escolhas produzam resultados agregados que estejam próximos de suas preferências individuais. Nesse sentido, todo sistema democrático representativo põe eleitores, políticos e partidos políticos diante de uma série de problemas de coordenação que ocorrem em diferentes níveis do sistema. Cox demonstrou que, mesmo em estados unitários com sistemas eleitorais majoritários e distritos uninominais, o efeito das regras eleitorais sobre o número de partidos não era direto. Dependia da maior ou menor capacidade - revelada por políticos e lideranças partidárias - de coordenar decisões sobre candidaturas, listas eleitorais, coligações e estratégias para a conquista de votos.

Segundo o autor, a configuração do sistema partidário depende dos incentivos produzidos pelo sistema eleitoral na medida em que este determina quais candidatos serão percebidos como competitivos. Um sistema eleitoral com regra de pluralidade e distritos uninominais cria 
incentivos para que os eleitores coordenem suas escolhas em torno de duas alternativas, enquanto a regra proporcional em distritos com magnitude elevada diminui a necessidade de coordenação, uma vez que existe um número maior de candidatos e partidos que são percebidos como eleitoralmente viáveis.

Como Cox, estamos interessados no fenômeno da coordenação eleitoral dado um arcabouço institucional que, no caso brasileiro, seguramente tende a dificultá-la.

\section{AS REGRAS DA DISPUTA POLÍTICA NOS MUNICÍPIOS}

Três conjuntos de instituição balizam a articulação do sistema partidário eleitoral local dos sistemas existentes nas demais esferas. O primeiro está constituído pelas regras que presidem a formação e a organização da esfera municipal de governo nos marcos da Federação. O segundo define o tipo de competição eleitoral e as características da representação política. O terceiro diz respeito à organização dos partidos. Esses três conjuntos podem ser encarados como sistemas de incentivo para o comportamento de partidos, políticos e eleitores, facilitando ou dificultando a articulação do sistema partidário eleitoral que perpassa os três níveis da Federação. Vejamos características e efeitos prováveis de cada um.

A Federação brasileira é composta por União, estados e municípios e constitui uma estrutura razoavelmente descentralizada. Adescentralização política foi um dos principais pontos da agenda da redemocratização no Brasil e beneficiou, sobretudo, os municípios.

Em consonância com o espírito da época, a Constituição de 1988 conferiu novo estatuto legal ao município, transformado em ente federati$\mathrm{vo}^{3}$, caso único nos sistemas federais contemporâneos. Obteve autonomia plena nos âmbitos político, administrativo, legislativo e financei$\mathrm{ro}^{4} \mathrm{e}$ adquiriu novas competências e atribuições. Ademais, foi o principal beneficiário da descentralização de recursos que se avolumaram com a ampliação das transferências constitucionais ${ }^{5}$.

A autonomia política significou a reafirmação da "capacidade de autogoverno", ou seja, eleição direta de prefeito, vice-prefeito e vereadores, o que já ocorria na maioria dos municípios, com exceção das capitais, estâncias hidrominerais e cidades consideradas especiais do ponto de vista da segurança nacional. A Carta de 1988, ao reiterar e univer- 
salizar normas constitucionais anteriores, estabeleceu eleições diretas e simultâneas para prefeito, vice-prefeito e vereadores, todos com mandato de quatro anos. Fixou também número de vereadores proporcional à população em distritos cuja magnitude varia entre 9 e $55^{6}$.

Como entes federativos, os municípios são dotados também de capacidade de auto-organização por meio de lei orgânica municipal própria ${ }^{7}$. Possuem, além disso, autonomia legislativa, ou seja, capacidade de legislar sobre assuntos de interesse local e de complementar as legislações estadual e federal.

A autonomia administrativa implica liberdade para organizar as atividades do governo local, criar o quadro de servidores municipais e criar ou suprimir distritos. Já a autonomia financeira se materializa na prerrogativa de criar e arrecadar os tributos próprios; elaborar, aprovar e executar o orçamento municipal e aplicar os recursos levadas em conta algumas limitações constitucionais (Neves, 2000:18-19; Rocha, 2001:31-32).

As normas constitucionais descritas anteriormente permitiriam a existência de sistemas políticos locais bastante independentes e desconectados dos demais níveis da Federação do ponto de vista da arregimentação partidária dos eleitores, da escolha dos governantes, da organização e do funcionamento dos poderes de governo. O município é uma arena de disputa eleitoral e de decisões de governo com perfil, instrumentos e recursos específicos. Quando se trata de formar o governo municipal, as escolhas dos eleitores podem ser feitas considerando apenas suas conseqüências prováveis no âmbito local. Políticos podem traçar estratégias de disputa por votos sem se preocupar com o que ocorre nas outras esferas da Federação; os partidos, na busca de êxito em pleitos municipais, têm de adaptar objetivos de escopo mais amplo às peculiaridades da competição em cada município.

Em função disso - considerando o ângulo que nos interessa aqui -, as regras que organizam a Federação estimulam a desconexão entre a competição política local e aquela que ocorre, em outro momento, nos estados e no âmbito nacional.

O que dizer dos incentivos provenientes das regras eleitorais? A discussão sobre o impacto de diferentes sistemas eleitorais sobre o formato dos sistemas de partidos é antiga (Duverger, 1954; 1986; Sartori, 1982; 1986; Rae, 1971; Grofman e Lijphart, 1986). Shugart e Carey 
(1992:207) acrescentaram uma segunda variável institucional relevante, além das regras eleitorais: os ciclos eleitorais, entendidos como o momento das eleições para o Executivo e o Legislativo.

Eleitores desejam o êxito eleitoral de seu candidato, políticos aspiram eleger-se, e partidos querem formar uma bancada expressiva. Para atingir seus objetivos, escolhem cursos de ação tomando em consideração as oportunidades e limitações criadas pelos diferentes sistemas eleitorais. Nem sempre as escolhas dos três tipos de agente vão no mesmo sentido; e essas escolhas, por seu turno, têm conseqüências sobre o formato do sistema partidário.

No que diz respeito a regras eleitorais, vigem no Brasil três sistemas diferentes: 1) majoritário de um só turno (pluralidade), com distritos uninominais na escolha de prefeitos em cidades com menos de 200 mil habitantes e senadores, e majoritário de um só turno (pluralidade), com distritos ora uni, ora binominais na escolha de senadores; 2 ) majoritário de dois turnos, em distritos de magnitude igual a 1, nas eleições para prefeitos de cidades com mais de 200 mil habitantes, governadores e presidente da República; 3) proporcional de lista aberta, com voto único transferível e distritos plurinominais, com magnitudes diversas, para a escolha de representantes nas câmaras municipais, assembléias estaduais e câmara federal. Não existe vinculação de voto para os diferentes tipos de pleito: os eleitores podem combinar no mesmo voto candidatos de distintos partidos.

$\mathrm{Na}$ formação dos legislativos municipais, as circunscrições eleitoral e político-administrativa se confundem; os limites do município definem o contorno dos distritos eleitorais plurinominais ${ }^{8}$.

De outra parte, há variação nos tipos de ciclo eleitoral. As eleições para presidência da República, governos estaduais, Senado, Câmara dos Deputados e assembléias legislativas coincidem. Já as eleições para Executivo e Legislativo nos municípios ocorrem em outro momento.

Sistema proporcional, lista aberta, possibilidade de desvinculação das escolhas em diferentes pleitos e ciclos eleitorais não-coincidentes aumentam a latitude de decisão dos eleitores e a autonomia dos políticos individuais com relação aos partidos. Os eleitores podem fazer suas próprias combinações de candidatos para distintos postos, cruzando fronteiras entre partidos. Os candidatos a cargos legislativos, para aumentar suas chances de êxito, são estimulados a negociar diferentes 
"dobradinhas" com candidatos a postos no Executivo ou no Legislativo de outra esfera da Federação. As combinações possíveis são muitas e podem atravessar fronteiras entre agremiações.

No sistema partidário brasileiro, há, portanto, um claro problema de coordenação decorrente do incentivo à competição intrapartidária produzido pelo sistema eleitoral, que combina fórmula proporcional e lista aberta com voto categórico em distritos de magnitude elevada. Em função disso, os partidos lidam não apenas com a competição interpartidária (ou intercoligações) mas também com uma forte competição intrapartidária. A visibilidade do político diante dos eleitores é decisiva na definição das chances de obter uma boa posição nas listas partidárias e, conseqüentemente, o mandato.

As lideranças partidárias, interessadas no controle dos Executivos e no aumento de suas bancadas nos Legislativos, têm de nadar contra a corrente buscando coordenar esse processo complexo de escolha e reduzir a desarticulação estimulada tanto pelas regras eleitorais quanto por características dos ciclos eleitorais. Nesse afã, nem todas as regras lhes são desfavoráveis. O fato de o distrito ser o mesmo para a disputa pelo Executivo e pelo Legislativo nos âmbitos estadual e municipal - ainda que as magnitudes difiram - facilita a coordenação entre os dois pleitos no mesmo nível da Federação. Pela mesma razão, a coincidência entre eleições nos estados e no plano federal facilita a coordenação dos pleitos para governadores, senadores, deputados federais e estaduais. A coordenação com o pleito presidencial é mais problemática ${ }^{9}$.

Já a existência de ciclos não-coincidentes para as disputas locais, bem como aquelas que ocorrem para os demais âmbitos da Federação, põe os partidos em face de desafios de coordenação específicos. Vejamos, por fim, os estímulos provenientes da legislação partidária.

A estrutura da Federação foi replicada na organização interna dos partidos pelo menos desde a Lei Orgânica dos Partidos, de 1971 (Lei no 5.697), que substituiu a Lei Orgânica, de 1965 (Lei no 4.740). De acordo com essa lei, os partidos deveriam estruturar-se em três níveis - muni$\operatorname{cipal}^{10}$, estadual e nacional. Na base da organização, as convenções escolhiam os candidatos aos postos do Executivo e do Legislativo, enquanto os diretórios indicavam a comissão executiva e o presidente, que se responsabilizavam pela gestão cotidiana do partido. A mesma estrutura se repetia nos planos estadual e nacional. As convenções municipais mandavam representantes à convenção estadual, que definia 
as candidaturas para todos os pleitos estaduais e nacionais cujo distrito eleitoral coincidisse com o Estado. Da mesma forma, delegados estaduais participavam da Convenção Nacional e da escolha do Diretório Nacional.

Essa estrutura que acompanha a arquitetura da Federação continuou vigente mesmo quando a Lei Orgânica foi substituída, em 1995, por uma nova legislação, que dá aos partidos liberdade para se organizar internamente como melhor lhes aprouver.

Mainwaring (1999:156-157) enfatiza - corretamente - que, nesse tipo de organização, políticos locais e, sobretudo, estaduais têm presença marcante nas decisões das instâncias nacionais. Chama assim a atenção para seu efeito potencialmente descentralizador. Os dirigentes estaduais teriam asseguradas uma significativa capacidade decisória nas instâncias nacionais ${ }^{11}$ e muita autonomia para definir sobre candidatos e coligações nos pleitos disputados em seu âmbito próprio de atuação. O mesmo ocorreria com dirigentes e organizações municipais.

Se isso é verdade, não é menos certo que a representação das organizações existentes em um nível, nas instâncias que lhes são superiores, estabelece conexões, por dentro da estrutura do partido, entre a política municipal e aquela que ocorre nos outros âmbitos. Essas conexões não garantem a coordenação entre pleitos, mas podem facilitá-la ao criar arenas institucionais de negociação.

De outra parte, as instituições informais que tendem a reger a vida partidária para além da legislação com freqüência aumentam a influência de poucos dirigentes de projeção nacional sobre as decisões. O grau em que isso ocorre depende da história da agremiação e da maneira como se estruturaram e cristalizaram os centros de poder internos. Assim é que, regidos pelo mesmo arcabouço de regras, o $\mathrm{PT}^{*}$ e o $\mathrm{PMDB}$ coordenam de maneira muito diversa os grupos e interesses existentes no plano local.

Que incentivos os políticos têm para produzir uma "reputação partidária" nesse contexto? Entendemos por reputação partidária a presença de uma imagem pública consistente com a imagem que o partido tem em outros níveis do sistema. Dessa forma, é possível esperar que o sistema apresente certo grau de previsibilidade quanto mais nítida for a percepção dessa reputação por parte dos eleitores. Pretendemos ofe- 
recer evidências empíricas de que os partidos são capazes de prover tal reputação, uma vez que os resultados eleitorais de um partido podem ser previstos com base nos resultados anteriores desse mesmo partido. Não apenas a criação, mas a manutenção de certa reputação partidária coloca-se como um problema de coordenação para os políticos: requer que os partidos tenham meios de controlar iniciativas individuais que possam vir a ser conflitantes com as posições programáticas da legenda. Quanto mais difícil for a provisão da reputação partidária, menor será a probabilidade de que o resultado eleitoral de um partido tenha correlação com seu desempenho em outras eleições no mesmo distrito.

\section{HIPÓTESES E DADOS}

Nossa hipótese principal é que os partidos conseguem coordenar suas campanhas de forma que a variação no desempenho de um partido em uma determinada eleição tenha efeito sobre o desempenho desse mesmo partido na eleição seguinte e em outras eleições que ocorrem no mesmo tempo. Se for possível estimar a votação de um partido com base em sua votação anterior ou em outros níveis, teremos uma evidência empírica de que são capazes de superar, em alguma medida, os efeitos desarticuladores produzidos pelo sistema político - em particular pela organização federativa e pelo sistema eleitoral - que dificultam a coordenação política.

Consideramos que a organização partidária é o fator subjacente responsável pela provisão desse bem público. $\mathrm{O}$ incentivo à organização, nos três níveis da Federação, resulta não só da lei de partidos políticos mas também do fato de que a existência do partido no município é importante para maximizar sua influência nos âmbitos estadual e nacional.

Em decorrência do número elevado de municípios na Federação em que os partidos estão presentes, a organização partidária não é uma dimensão facilmente observável do sistema partidário. Tratamos de explorá-la com base na análise da correlação entre as proporções de votos dos partidos nos municípios em diferentes eleições. Caso o sistema partidário não tivesse um nível mínimo de organização no nível municipal, os resultados eleitorais tenderiam a apresentar correlações fra-

Ver lista de siglas dos partidos políticos, com os respectivos significados, no final deste artigo. 
cas ou inexistentes. O nível escolhido para testar a hipótese formulada - o município - é bastante exigente, uma vez que nem todas as eleições consideradas têm o município como distrito.

Nosso teste empírico considera também uma hipótese secundária: o sistema partidário brasileiro atual não apresenta subsistemas diferenciados segundo o tamanho do município.

A literatura sobre o período 1946-1964 indicava a presença de subsistemas partidários nos estados, definidos "em função do número de partidos relevantes e da fragmentação eleitoral" (Lima Junior, 1983:67), e uma grande diferença na distribuição da força relativa dos partidos segundo o tamanho dos municípios. De acordo com Campello de Souza (1976), havia um subsistema competitivo nas principais capitais dos estados e outro não-competitivo que prevalecia nos pequenos municípios do interior. Embora nosso objetivo não seja fazer um contraponto direto às hipóteses de Lima Junior e de Campello de Souza sobre o sistema de partidos no regime de 1946, incluímos nos modelos de regressão discutidos mais adiante variáveis dummies com o propósito de controlar as estimativas dos coeficientes pelas diferenças no tamanho dos municípios. Dummies não-significativas indicam ausência de diferenças entre municípios segundo o tamanho da população, mantendo constantes as demais variáveis dos modelos.

A amostra utilizada consiste de um painel de municípios com os resultados das eleições para presidência da República, Câmara Federal, governos estaduais e assembléias estaduais de 1994 e 1998, e para prefeituras e câmaras municipais de 1996 e 2000. Os dados das eleições estaduais e nacionais foram desagregados por município, integrados em uma mesma base com as eleições municipais e organizados em uma matriz de 38.591 linhas com a votação dos sete partidos selecionados nos 5.513 municípios para os quais temos informações. As variáveis utilizadas descrevem a proporção de votos dos sete maiores partidos brasileiros - PMDB, PFL, PSDB, PPB ${ }^{12}$, PTB, PT e PDT. Estes receberam em média 90\% dos votos nas eleições nacionais e estaduais de 1994 e 1998, e 82\% dos votos nas eleições locais de 1996 e 2000, percentuais calculados com base na proporção média dos votos de cada partido nos municípios da amostra (ver Tabela 1 do Anexo). O PMDB é o partido que tem a maior proporção média de votos nos municípios em quatro das cinco eleições estaduais e locais consideradas. Na única eleição em que não ocupa o primeiro lugar - para deputado federal em 1998 -, fica 
em segundo lugar, com uma média de $22 \%$ dos votos nos 5.511 casos para os quais temos informações. Partidos coligados em eleições nacionais, estaduais ou municipais, que não tinham o candidato principal, aparecem com uma proporção de votos igual a zero.

A Tabela 1, a seguir, apresenta o número de casos em cada ano do painel e o percentual de casos sem informação. Os municípios foram classificados segundo faixas de tamanho da população com base no Censo Demográfico $2000^{13}$. Dessa forma, não consideramos as variações longitudinais no tamanho da população dos municípios. Adicionalmente, tivemos de lidar ainda com a variação no número de municípios no Brasil entre 1994 e 2000. No período considerado, são criados 544 municípios. Essa variação tem efeito direto sobre o número de casos válidos nas análises em que são consideradas eleições ocorridas em diferentes anos. Nos modelos de I a IV, por exemplo, o número de casos válidos é de 4.944, o que significa uma perda de 569 casos com relação ao ano de $2000(\mathrm{~N}=5.513)$. Desse total de casos perdidos, $544(95,6 \%)$ decorreram do fato de o município ter sido criado após 1994 (primeiro ano do painel). No modelo V, apenas com as eleições de 1998 e 2000, o número de casos válidos sobe para 5.403 (1,9\% de casos perdidos).

Tabela 1

Informações sobre o Painel de Municípios

\begin{tabular}{c|c|c|c}
\hline $\begin{array}{c}\text { Anos Incluídos } \\
\text { no Painel }\end{array}$ & $\begin{array}{c}\text { Número de Municí- } \\
\text { pios em que Houve } \\
\text { Eleições }\end{array}$ & $\begin{array}{c}\text { Municípios com Re- } \\
\text { sultados Eleitorais } \\
\text { Conhecidos (N) }\end{array}$ & $\begin{array}{c}\text { Percentual de Mu- } \\
\text { nicípios sem Infor- } \\
\text { mação }\end{array}$ \\
\hline 1994 & 5.112 & 5.017 & $-1,9 \%$ \\
1996 & 5.598 & 5.404 & $-3,5 \%$ \\
1998 & 5.608 & 5.511 & $-1,7 \%$ \\
2000 & 5.656 & 5.513 & $-2,5 \%$ \\
\hline
\end{tabular}

Fontes: TSE e IBGE, “Perfil dos Municípios Brasileiros" e “Sinopse Preliminar do Censo 2000".

\section{MODELOS E SUPOSIÇÕES}

Os modelos utilizados neste artigo inspiram-se na análise de Lavareda (1991) sobre o sistema partidário do período 1946-1964. O autor utilizou "a análise das correlações entre os graus de fracionamento eleitoral assumidos pelas diversas categorias de pleitos" como medida proxy da articulação entre níveis do sistema partidário (ibidem:128). A hipótese formulada por ele sobre a consolidação do sistema partidário no período foi testada com base apenas em um indicador sistêmico: o índice 
de fracionamento. A análise da correlação do grau de fracionamento uma medida do formato do sistema partidário -, nas diferentes eleições do período, fundamentou sua inferência sobre a "pluralização" dos subsistemas estaduais e, conseqüentemente, sobre a "nacionalização das forças partidárias", um tema importante na literatura sobre partidos e eleições do período 1945-1962 (Soares, 1973; Souza, 1976; Lima Junior, 1983).

Como a hipótese proposta por Lavareda (1991) dizia respeito, sobretudo, à nacionalização do sistema partidário, seria mais apropriado testá-la considerando variáveis que descrevessem a força relativa dos partidos nos estados e municípios da Federação, a exemplo do que realizamos no presente estudo. O trabalho de Lavareda apresenta ainda outras limitações metodológicas importantes. Em primeiro lugar, não analisa longitudinalmente os dados eleitorais, mas somente a variação entre os estados (análise cross-sectional); nesse sentido, seu modelo não leva em conta diretamente o efeito do tempo sobre a competição eleitoral. Em segundo lugar, não há nenhuma indicação de que seu esquema causal tenha considerado os efeitos indiretos. Por fim, para representar a articulação entre diferentes eleições, foram estimados apenas coeficientes de correlação bivariados.

A análise realizada neste artigo buscou superar essas limitações. Nossa hipótese principal é que existe um padrão de articulação entre os diferentes níveis do sistema partidário brasileiro e que o subsistema partidário local se encontra articulado aos subsistemas estadual e nacional. Nesse sentido, os testes empíricos apresentados permitem avaliar se o desempenho do partido em uma eleição e em um município qualquer tem um efeito diacrônico sobre o desempenho desse mesmo partido na próxima eleição e sincrônico nos pleitos para outros cargos que ocorrem na mesma eleição. Antes de apresentarmos as hipóteses operacionais que testamos, é necessário considerar a estrutura das relações existentes entre os diferentes subsistemas partidários no Brasil, representadas no Quadro a seguir.

A representação dos modelos de regressão por Mínimos Quadrados em Dois Estágios - MQ2E, em diagramas causais, permite visualizar as variáveis endógenas consideradas nas estimativas. Apresentamos esquemas causais simplificados com o objetivo de facilitar a visualização das interações atribuídas aos diferentes níveis do sistema partidário. A disposição das variáveis segue a ordem temporal. De forma simplifica- 
Definindo a Arena Política Local...

\section{Quadro 1}

Especificação dos Modelos MQ2E para Estimar os Determinantes das Proporções de Voto dos Partidos em Diferentes Subsistemas Partidários

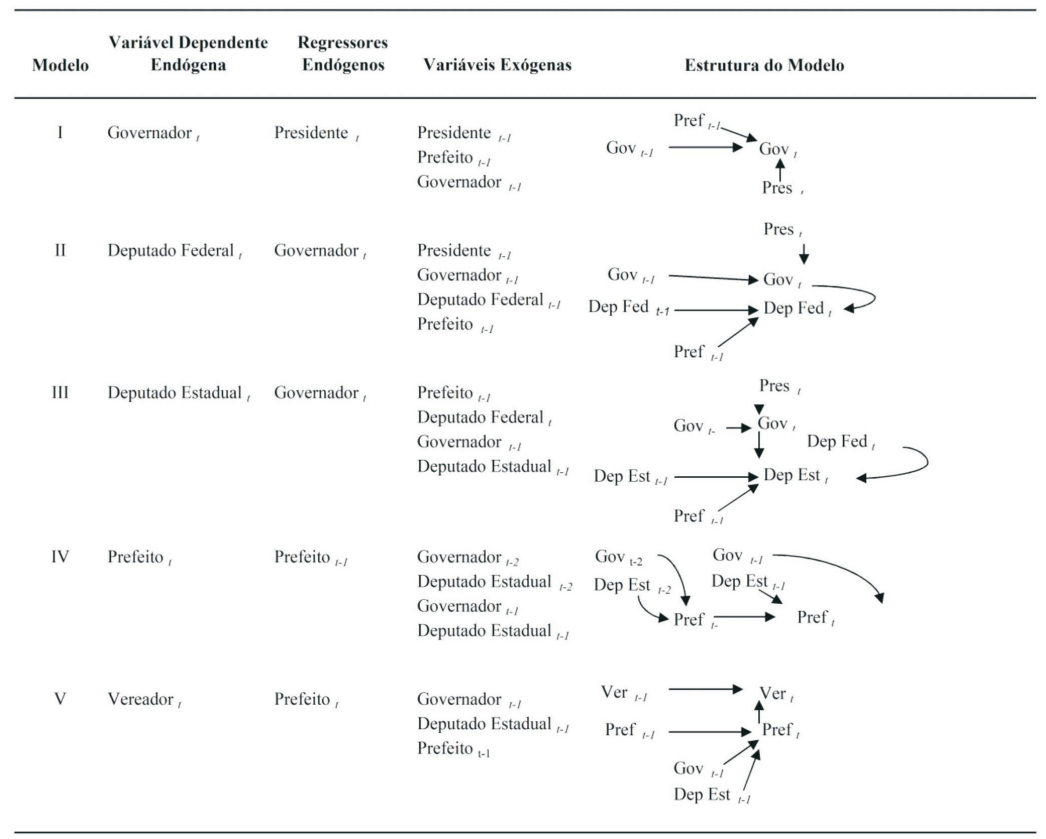

Elaboração dos autores.

da, consideramos as eleições em três tempos: $t, t-1$ e $t$-2. A indicação de tempo $t-2$ aparece apenas no modelo IV, em que as eleições para governador em 1994 (t-2) e 1998 (t-1) são incluídas como regressores das eleições para prefeito em $t$ e em $t$-1.

Os modelos foram construídos com base nas seguintes suposições:

Suposição 1. As relações de causalidade ${ }^{14}$, no âmbito do sistema partidário, podem ser consideradas não-recursivas. Essa simplificação é obviamente adequada nos casos em que há assimetria temporal entre as variáveis. No entanto, no caso de pleitos simultâneos, a direção da causalidade atribuída aos modelos é arbitrária e exige uma justificativa específica, oferecida na suposição a seguir.

Suposição 1.1. Como no período 1945-1965, as eleições para governador são consideradas o elemento articulador do sistema ${ }^{15}$. Em conseqüên- 
cia, a eleição para governador foi representada como uma variável exógena nos cinco modelos apresentados.

Suposição 1.2. Eleições do subsistema majoritário foram consideradas variáveis independentes para estimar a proporção de votos dos partidos nas eleições proporcionais (estaduais ou locais). Dessa forma, as eleições para governador têm efeito sobre as eleições para deputado estadual e federal, e as eleições para prefeito sobre as eleições para vereador.

Suposição 1.3. As eleições para deputado federal têm efeito direto sobre as eleições para deputado estadual. As "dobradinhas" refletem a preferência dos candidatos à Câmara Federal, que escolhem os candidatos a deputado estadual com quem irão trabalhar.

Suposição 2. Os modelos são independentes: cada tipo de eleição é explicado por um modelo causal específico. O objetivo não é testar uma hipótese geral sobre o sistema partidário em seu conjunto, mas hipóteses específicas sobre os determinantes de cada um dos tipos de eleição considerados. Assim, no Quadro 1, a votação para prefeito aparece no modelo I como um regressor exógeno da votação para governador. No modelo II, esse efeito não é considerado e verifica-se que a votação para deputado federal está correlacionada com a votação para prefeito. Dessa forma, podemos testar se as eleições locais têm impacto direto em diferentes pontos do sistema partidário estadual. Caso a estrutura do modelo fosse fixa, e se fosse considerado apenas o efeito da eleição para prefeito sobre as eleições para governador, não seria possível estimar seus impactos em outros pontos do sistema.

O teste das hipóteses, como indicam as suposições dos modelos, situa-se no nível do sistema partidário. No entanto, os resultados empíricos permitem inferências sobre o papel da organização partidária no funcionamento do sistema, como sugerimos anteriormente.

Os determinantes da votação para governador, representados no modelo I, foram estimados com base no método dos Mínimos Quadrados Ordinários - MQO, ao passo que, nos modelos II, III e IV, utilizamos o método dos $\mathrm{MQ2} \mathrm{E}^{16}$. A utilização desse método permite estimar os coeficientes para uma única equação a partir de um sistema de equações, não sendo necessário especificar a forma funcional das demais equações do sistema. As distribuições das variáveis (ver, a seguir, a discussão sobre resultados dos modelos) indicaram a necessidade de recor- 
rer a estimativas pela razão de verossimilhança com base no método Tobit para dados censurados ${ }^{17}$. Distribuições não-normais com zeros inflacionados, como as que estamos trabalhando, podem produzir estimativas enviesadas e não-confiáveis dos coeficientes quando estes são estimados pelo método dos mínimos quadrados. Em função disso, optamos por estimar nossos modelos segundo esses dois métodos diferentes.

Nos modelos de regressão, incluímos um conjunto de variáveis dummies para controlar pelo efeito do tamanho do município. Os municípios foram divididos em quatro categorias: menos de 10 mil habitantes; de 10 a 50 mil; de 50 a 200 mil; e mais de 200 mil. As categorias de tamanho foram definidas com o objetivo de garantir um número suficiente de casos na categoria acima de 200 mil habitantes (106 municípios) e também para controlar o efeito dos municípios muito pequenos, onde, supostamente, o sistema partidário pode apresentar maior fluidez e desorganização. Por questões de economia, não as apresentamos nos modelos descritos a seguir, mas as incluímos em todas as equações especificadas, cujos resultados aparecem na Tabela $3^{18}$.

No modelo I, a votação de um partido nas eleições para governador, em um município qualquer, tem efeito direto sobre a votação desse mesmo partido nas eleições seguintes para o mesmo cargo. A votação do partido é determinada também pela votação recebida nas eleições para prefeito em $t-1$ e para presidente em $t$. Nesse modelo, não consideramos o efeito da eleição para presidente em $t-1$ como uma variável exógena. Ele é um modelo de regressão $\mathrm{MQO}$ com estimativa robusta e a seguinte forma:

$Y_{\operatorname{gov}(t)}=\beta_{0}+\beta_{1} \operatorname{gov}_{(t-1)}+\beta_{2} \operatorname{pres}_{(t)}+\beta_{3} \operatorname{pref}_{(t-1)}+\varepsilon \quad$ Modelo I

No modelo II, a votação para deputado federal na eleição no tempo $t$, em um município qualquer, tem a votação para governador em $t$ como regressor endógeno, que é determinado pela votação do partido para governador em $t$-1 e para presidente em $t$. À diferença do modelo I, a eleição para prefeito em $t$ - 1 foi considerada um regresspr exógeno com efeito direto sobre a votação para deputado federal en $t$, juntamente com a eleição para deputado federal em $t$-1.

$$
\begin{aligned}
& Y_{\text {depfed }(t)}=\beta_{0}+\beta_{1} \operatorname{depfed}_{(t-1)}+\beta_{2} \operatorname{gov}_{(t)}+\beta_{3} \operatorname{pref}_{(t-1)}+v \\
& Y_{\operatorname{gov}(t)}=\beta_{0}+\beta_{1} \operatorname{gov}_{(t-1)}+\beta_{2} \operatorname{pres}_{(t)}+\tau
\end{aligned}
$$


A votação para deputado estadual, modelo III, tem a votação para governador em $t$ como regressor endógeno determinado pela votação do partido para governador em $t$-1 e para presidente em $t$. As votações nas eleições para deputado estadual e prefeito em $t$ - 1 e deputado federal em $t$ são os regressores exógenos do modelo. A suposição 1.3 - sobre a composição das "dobradinhas" - permitiu-nos fixar o sentido do efeito da votação para deputado federal sobre a votação para deputado estadual.

$Y_{\text {depest }(t)}=\beta_{0}+\beta_{1} \operatorname{depfed}_{(t)}+\beta_{2} \operatorname{gov}_{(t)}+\beta_{3} \operatorname{pref}_{(t-1)}+\beta_{3} \operatorname{depest}_{(t-1)}+v$

$Y_{\operatorname{gov}(t)}=\beta_{0}+\beta_{1} \operatorname{gov}_{(t-1)}+\beta_{2} \operatorname{pres}_{(t)}+\tau$

Modelo III

Os modelos IV e V têm como variáveis dependentes as votações dos partidos nas eleições locais para prefeito e vereador, e permitem uma discussão mais abrangente sobre as articulações entre níveis do sistema partidário. À eleição para governador, como nos modelos anteriores, foi atribuída uma série de efeitos indiretos que atingem todo o sistema. Por exemplo: no modelo IV, a votação de um partido na eleição para governador tem um efeito direto na votação desse mesmo partido nas eleições para prefeito que ocorrem no pleito subseqüente e um efeito indireto (eleição para governador em $t$-2) via votação para prefeito que ocorre no tempo $t-1$. No modelo $V$, a votação para prefeito é endogenamente determinada pelas votações para prefeito, deputado estadual e governador obtidas em $t$-1. Já a votação nas eleições para prefeito tem impacto sobre a votação para vereador do partido, que tem como regressor externo a votação para vereador em $t-1$.

$\mathrm{Y}_{\text {pref }(t)}=\beta_{0}+\beta_{1} \operatorname{gov}_{(t)}+\beta_{2} \operatorname{pref}_{(t-1)}+\beta_{3} \operatorname{depest}_{(t-1)}+v$

$Y_{\text {pref(t-1) }}=\beta_{0}+\beta_{1} \operatorname{gov}_{(t-1)}+\beta_{2} \operatorname{depest}_{(t-1)}+\tau$

Modelo IV

$Y_{\operatorname{ver}(t)}=\beta_{0}+\beta_{1} \operatorname{pref}_{(t)}+\beta_{2} \operatorname{ver}_{(t-1)}+v$

$Y_{\text {pref }(t)}=\beta_{0}+\beta_{1} \operatorname{gov}_{(t-1)}+\beta_{2} \operatorname{pref}_{(t-1)}+\beta_{3} \operatorname{depest}_{(t-1)}+\tau$

Modelo V

\section{RESULTADOS DOS MODELOS E DISCUSSÃO}

A Tabela 2, a seguir, apresenta as estatísticas descritivas das onze variáveis que utilizamos para estimar os parâmetros dos modelos de I a V. O problema do número de casos válidos já foi analisado no item dedica- 
do a comentar a estrutura do painel. Há 128 municípios nas eleições para prefeito de 2000 e 141 municípios nas eleições de 1996, em que um único partido obteve $100 \%$ dos votos. Respectivamente, $82 \%$ e $83 \%$ desses casos ocorreram em municípios com menos de 10 mil habitantes. Nas eleições para vereador, houve apenas dois casos em que um único partido obteve $100 \%$ dos votos. Optamos por apresentar informações sobre a mediana e o $25^{\circ}$ percentil na medida em que as distribuições apresentam problemas de kurtosis acentuada e cauda na direção dos maiores valores (skewness).

Tabela 2

Estatísticas Descritivas das Variáveis Incluídas nos Modelos

\begin{tabular}{l|c|c|c|c|c|c|c|c}
\hline Eleição/Ano & Variável & $\mathbf{N}$ & Média & $\begin{array}{c}\text { Desvio } \\
\text { Padrão }\end{array}$ & $\mathbf{2 5 ^ { \circ }}$ Percentil & Mediana & Mínimo & Máximo \\
\hline Presidente/1998 & presp98 & 5.513 & 0,121 & 0,22 & 0,00 & 0,00 & 0 & 0,90 \\
Governador/1998 & govp98 & 5.513 & 0,134 & 0,22 & 0,00 & 0,00 & 0 & 0,96 \\
Governador/1994 & govp94 & 5.017 & 0,131 & 0,20 & 0,00 & 0,01 & 0 & 0,94 \\
Deputado federal/1998 & dfp98 & 5.513 & 0,129 & 0,18 & 0,01 & 0,05 & 0 & 0,99 \\
Deputado federal/1994 & dfp94 & 5.017 & 0,131 & 0,18 & 0,01 & 0,05 & 0 & 0,98 \\
Deputado estadual/1998 & depest98 & 5.511 & 0,119 & 0,16 & 0,01 & 0,04 & 0 & 0,98 \\
Deputado estadual/1994 & depest94 & 5.017 & 0,123 & 0,17 & 0,01 & 0,05 & 0 & 0,99 \\
Prefeito/2000 & prefp00 & 5.513 & 0,121 & 0,21 & 0,00 & 0,00 & 0 & 1,00 \\
Prefeito/1996 & prefp96 & 5.404 & 0,124 & 0,21 & 0,00 & 0,00 & 0 & 1,00 \\
Vereador/2000 & verp00 & 5.513 & 0,113 & 0,13 & 0,00 & 0,07 & 0 & 1,00 \\
Vereador/1996 & verp96 & 5.403 & 0,119 & 0,14 & 0,00 & 0,07 & 0 & 1,00 \\
\hline
\end{tabular}

Elaboração dos autores.

A matriz de correlação, Tabela 2 do Anexo, indica apenas uma eleição cujos resultados apresentam correlação negativa, embora bastante fraca, com as demais: as eleições presidenciais de 1998. Essa eleição envolveu a disputa do segundo mandato de Fernando Henrique Cardoso e foi polarizada, desde o primeiro turno, entre o PT e o PSDB. Optamos por imputar uma proporção de votos igual a zero a todos os partidos que não lançaram candidatos nessas eleições ${ }^{23}$. Dessa forma, submetemos nossas hipóteses a um teste empírico bastante rígido, uma vez que a participação de um partido em uma coligação nacional ou estadual, com o candidato à vice, por exemplo, não significa que esse partido não tenha tido uma presença organizada na campanha travada em nível local. Estamos, nesse sentido, desconsiderando uma parte significativa da coordenação que de fato pode existir no âmbito do sistema partidário. Optamos por esse procedimento não apenas porque facilita a acei- 
tação da hipótese nula ${ }^{24}$ do estudo mas também em virtude dos problemas de imputação em que incorreríamos ao tentar atribuir uma proporção qualquer de votos em cada um dos municípios correspondentes aos partidos em posição secundária na coligação.

Essas informações são importantes para a definição do método a ser utilizado para estimar os parâmetros das equações dos modelos de I a V. Em função dessa análise, além das estimativas por MQ2E, optamos por estimar também os coeficientes por Tobit, o que significa considerar as variáveis dependentes como latentes ${ }^{25} \mathrm{e}$ limitadas à esquerda e à direita em virtude de problemas de observação. Substantivamente, ao tratarmos as variáveis dependentes como latentes, assumimos que os partidos têm algum nível de organização nos municípios que não pode ser diretamente observado, como no caso das coligações em que os votos recebidos pelos partidos coligados foram contabilizados como votos apenas do partido que encabeça a coligação. As três últimas linhas da Tabela 3 indicam o número de casos não censurados e censurados à esquerda e à direita em cada um dos modelos ${ }^{26}$.

A Tabela 3 apresenta ainda o $R^{2}$ ajustado para os modelos MQ2E e o logaritmo da razão de verossimilhança $\left(\mathrm{LR} \chi^{2}\right)$ para os modelos Tobit. Há diferenças importantes entre os modelos no que diz respeito à capacidade explicativa: o modelo I tem um $\mathrm{R}^{2}$ de 0,18 , enquanto o modelo $\mathrm{V}$, apenas com eleições locais, apresenta um $\mathrm{R}^{2}$ de 0,59 . Ele é o modelo com o melhor ajuste entre os cinco estimados.

Os coeficientes estimados por Tobit indicam efeitos em geral maiores das variáveis independentes, uma vez que as observações com valor zero nas variáveis dependentes tiveram seu peso reduzido nas estimativas. Com efeito, os coeficientes estimados por Tobit são maiores em onze das quinze estimativas realizadas. Os resultados dos modelos de regressão por MQ2E e Tobit são convergentes em um aspecto central para nossa hipótese: todos os coeficientes das variáveis independentes, nos cinco modelos, são positivos e significativos. Nesse sentido, os métodos utilizados nas estimativas não conduzem a conclusões discrepantes com relação à hipótese central: os partidos conseguem coordenar suas campanhas de forma que a variação no desempenho de um partido em uma determinada eleição tenha efeito sobre o desempenho desse mesmo partido na eleição seguinte e em outras eleições que ocorrem no mesmo tempo. A hipótese estabelece, portanto, duas fontes de articulação no âmbito do sistema: entre níveis e diacrônica. 
Tabela 3

Determinantes das Proporções de Voto dos Partidos em Diferentes Subsistemas Partidários:

Estimativas dos Modelos de Regressão por MQ2E e Tobit

(com dados censurados à esquerda e à direita)

\begin{tabular}{|c|c|c|c|c|c|c|c|c|c|c|}
\hline \multirow{5}{*}{$\begin{array}{l}\text { Variáveis } \\
\text { Independentes }\end{array}$} & \multicolumn{10}{|c|}{ Variáveis Dependentes } \\
\hline & \multicolumn{6}{|c|}{ Sistema Nacional e Subsistemas Estaduais } & \multicolumn{4}{|c|}{ Subsistemas Locais } \\
\hline & \multicolumn{2}{|c|}{$\begin{array}{c}\text { (I) } \\
\text { Governador } \\
\end{array}$} & \multirow{2}{*}{\multicolumn{2}{|c|}{$\begin{array}{c}\text { (II) } \\
\text { Dep. Fed.t }\end{array}$}} & \multicolumn{2}{|c|}{$\begin{array}{c}\text { (III) } \\
\text { Dep. Est. } t\end{array}$} & \multirow{2}{*}{\multicolumn{2}{|c|}{$\begin{array}{c}(\mathrm{IV}) \\
\text { Prefeito }_{t}\end{array}$}} & \multirow{2}{*}{\multicolumn{2}{|c|}{$\begin{array}{c}(\mathrm{V}) \\
\text { Vereador }_{t}\end{array}$}} \\
\hline & & & & & & & & & & \\
\hline & MQ2E & lobit & MQ2E & Tobit & MQ2E & Tobit & MQ2E & Tobit & MQ2E & Tobit \\
\hline \multicolumn{11}{|l|}{ Efeitos Diacrônicos } \\
\hline \multirow{2}{*}{ Governador $t-1$} & $0,321^{* *}$ & $0,577^{* *}$ & & & & & $0,109 * *$ & $0,422^{* *}$ & & \\
\hline & 0,008 & 0,012 & & & & & 0,009 & 0,016 & & \\
\hline \multirow{2}{*}{ Dep. Federal $_{t-1}$} & & & $0,246^{* *}$ & $0,393^{* *}$ & & & & & & \\
\hline & & & 0,011 & 0,005 & & & & & & \\
\hline \multirow[t]{2}{*}{ Dep. Estadual $t-1$} & & & & & $0,205^{* *}$ & $0,239^{* *}$ & $0,172^{* *}$ & $0,644^{* *}$ & & \\
\hline & & & & & 0,008 & 0,005 & 0,014 & 0,022 & & \\
\hline \multirow[t]{2}{*}{ Prefeito $t-1$} & $0,210^{* *}$ & $0,353^{* *}$ & $0,072^{* *}$ & $0,162^{* *}$ & $0,063^{* *}$ & $0,085^{* *}$ & $0,471^{* *}$ & $0,337^{* *}$ & & \\
\hline & 0,007 & 0,011 & 0,007 & 0,004 & 0,005 & 0,004 & 0,029 & 0,019 & & \\
\hline Vereador $t-1$ & & & & & & & & & $0,265^{* *}$ & $0,500^{* *}$ \\
\hline
\end{tabular}


Tabela 3

Determinantes das Proporções de Voto dos Partidos em Diferentes Subsistemas Partidários:

Estimativas dos Modelos de Regressão por MQ2E e Tobit

(com dados censurados à esquerda e à direita)

(continuação) 
Tabela 3

Determinantes das Proporções de Voto dos Partidos em Diferentes Subsistemas Partidários:

Estimativas dos Modelos de Regressão por MQ2E e Tobit

(com dados censurados à esquerda e à direita)

(continuação)

Variáveis

Independentes
Variáveis Dependentes

Sistema Nacional e Subsistemas Estaduais

(I)

(II)

(III)

Dep. Est.

\begin{tabular}{ccccccccccc}
\multicolumn{2}{c}{ Governador $\boldsymbol{t}$} & \multicolumn{2}{c}{ Dep. Fed. $\boldsymbol{t}$} & \multicolumn{2}{c}{ Dep. Est. $\boldsymbol{t}$} & \multicolumn{2}{c}{ Prefeito $_{\boldsymbol{t}}$} & \multicolumn{2}{c}{ Vereador $_{\boldsymbol{t}}$} \\
\hline MQ2E & Tobit & MQ2E & Tobit & MQ2E & Tobit & MQ2E & Tobit & MQ2E & Tobit \\
\hline 0,002 & 0,015 & 0,002 & 0,006 & 0,002 & 0,005 & 0,003 & 0,020 & 0,002 & 0,004 \\
0,003 & 0,000 & 0,000 & 0,003 & $-0,001$ & $-0,004$ & 0,003 & $-0,016$ & 0,004 & 0,007 \\
0,002 & 0,016 & 0,002 & 0,006 & 0,002 & 0,005 & 0,003 & 0,022 & 0,002 & 0,004
\end{tabular}

Variáveis Exógenas

Presidente

Presidente

Governador $t-2$

Governador $_{t-1}$

Governador $_{t-1}$

Dep. Estadual $t-2$

Governador $t-1$

Dep. Estadual $t-1$

Prefeito $t-1$

$\begin{array}{lccccccccccc}\text { Constante } & 0,051^{* *} & -0,209^{* *} & 0,011^{* *} & 0,066^{* *} & 0,017^{* *} & 0,036^{* *} & 0,023^{* *} & -0,261^{* *} & 0,013 & 0,067^{* *} \\ \mathrm{R}^{2} / \mathrm{LR} \chi^{2} & 0,18 & 5.387^{* *} & 0,33 & 13.237^{* *} & 0,37 & 15.191^{* *} & 0,24 & 4.771^{* *} & 0,59 & 20.778^{* *} \\ \mathrm{~N} & 34.607 & 34.607 & 34.607 & 34.606 & 34.607 & 34.606 & 34.607 & 35.120 & 37.821 & 37.821\end{array}$

34.607

34.607

4.607

4.607

24.294

9.591

À esquerda $(Y \leq 0)$

19.898

649

309

10.641

28.211

Não censurados

14.341

33.653

34.121

185

19

368

177

(a) A categoria de referência indica cidades com mais de 200 mil habitantes (dummy omitida).

Elaboração dos autores 
A existência de articulação entre níveis do sistema partidário, tanto no subsistema majoritário quanto no proporcional, foi confirmada nos cinco modelos testados. Há efeitos significativos das votações para prefeito e presidente sobre as votações para governador (modelo I); das votações para prefeito e governador sobre as votações para deputado federal (modelo II); das votações para prefeito, governador e deputado federal sobre as votações para deputado estadual (modelo III); das votações para governador e deputado estadual sobre as votações para prefeito (modelo IV); e das votações para prefeito sobre as votações para vereador (modelo V).

As estimativas obtidas indicam que, nas eleições majoritárias (governador e prefeito), o fator de articulação mais importante é diacrônico: a votação recebida pelos partidos em eleições anteriores para os cargos majoritários é o que tem o maior efeito sobre a votação do partido nas eleições seguintes para esses mesmos cargos. Essa hipótese é confirmada nos modelos I e IV pelas estimativas por MQ2E. No modelo I, um aumento de 10 pontos percentuais na votação de um partido qualquer nas eleições para governador produz uma mudança esperada na votação seguinte de 5,7 pontos, estimada por Tobit, ou de 3,2 pontos, estimada por MQ2E, mantendo-se constantes as demais votações do partido. Nas eleições para prefeito, modelo IV, um aumento de 10 pontos percentuais produz um aumento esperado de 4,7 pontos na votação seguinte, estimado por MQ2E, ou de 3,37 pontos, estimado por Tobit, mantendo-se as demais votações constantes.

As evidências não são conclusivas com relação ao papel desempenhado pelas eleições majoritárias no sistema. Com base nas estimativas por MQ2E, podemos concluir que a votação para governador é a variável que tem o maior efeito sobre as votações para deputado federal e estadual; e a votação para prefeito é a que tem o maior efeito sobre a votação para vereador. Em resumo, essas são evidências de que o subsistema majoritário organiza o subsistema proporcional. No entanto, esses resultados não foram confirmados nas estimativas por Tobit, que apontam a articulação diacrônica como o principal fator do sistema, mesmo no subsistema proporcional. As votações para deputados federal e estadual sofrem o impacto sobretudo das votações anteriores para esses mesmos cargos.

As variáveis dummies foram incluídas nos modelos com o objetivo de permitir um teste da hipótese de que o sistema partidário brasileiro 
atual não apresenta subsistemas diferenciados de acordo com o tamanho do município. As dummies indicam, precisamente, a presença de efeitos específicos associados ao tamanho do município ${ }^{27}$. De maneira geral, não constatamos efeitos sistemáticos associados ao tamanho do município. Encontramos efeitos significativos em apenas três modelos estimados por MQ2E para os municípios com menos de 10 mil habitantes (modelos II, III e IV) e de 10 a 50 mil (modelos II e V). Nos modelos estimados por Tobit, encontramos apenas uma dummy para os municípios com menos de 10 mil habitantes, significativa para o nível de teste de 0,05 no modelo IV. Esses resultados sugerem que podemos igualmente aceitar a hipótese de que o sistema partidário brasileiro não apresenta subsistemas diferenciados segundo o tamanho do município. A continuidade de subsistemas diferenciados na esfera local, um argumento persistente na imaginação política brasileira, não encontra confirmação empírica nesses resultados.

Esses resultados confirmam a existência de um padrão consistente de estruturação das disputas eleitorais no sistema partidário brasileiro, mas deixam uma pergunta importante a ser respondida: em que medida a organização partidária, tal como a definimos, é o fator subjacente responsável pela provisão desse bem público? A resposta pode ser derivada das suposições teóricas adotadas. Como afirmamos, a organização de um sistema partidário nacional envolve sempre diferentes problemas de coordenação que podem ser "resolvidos" se os eleitores votam de forma instrumental, ou seja, se calculam a probabilidade de que suas escolhas produzam resultados agregados que estejam próximos de suas preferências individuais. O papel dos partidos, nessa perspectiva, é de elemento articulador entre as escolhas locais e as políticas regional e nacional. Os resultados encontrados assinalam, portanto, o efeito da organização partidária na definição do que chamamos "articulação entre níveis do sistema partidário brasileiro".

Nosso objetivo neste artigo foi lançar luz sobre a política local, dimensão ainda pouco conhecida do sistema democrático brasileiro. Baseados apenas na análise de resultados eleitorais, buscamos testar hipóteses aceitas sobre a natureza da competição político-eleitoral no âmbito municipal e sobre sua relação com o que ocorre nos estados. A dinâmica político-eleitoral nos municípios não pode ser entendida como expressão apenas das forças que se movem em seu território. Nos marcos da Federação, uma trama complexa de relações entrelaça os municípios às esferas estadual e nacional. 
A análise mostrou que há coordenação política. É provável que ela exista em níveis mais elevados do que aqueles que pudemos medir. Nossos modelos não tomam em consideração as coligações eleitorais, que constituem mecanismos importantes de coordenação. Na medida em que quebramos os resultados eleitorais de todos os pleitos por município, também deixamos de lado o efeito sobre as eleições locais dos resultados agregados dos pleitos nos quais os distritos eleitorais são os estados.

A despeito dos incentivos institucionais e na contramão da sabedoria convencional, o sistema partidário brasileiro apresenta indícios de vertebração na medida em que articula a competição por votos nas três esferas da Federação. O município e a política local não podem ser adequadamente descritos como pertencentes a uma arena fechada à influência das disputas travadas em outros âmbitos do sistema partidário brasileiro.

(Recebido para publicação em março de 2006) (Versão definitiva em abril de 2008) 


\section{NOTAS}

1. Antes dele, Lima Junior (1983) tratou do impacto da Federação sobre o sistema vigente entre 1946 e 1965.

2. "A natureza ideológica de um determinado partido varia consideravelmente de um estado para outro. Além disso, às vezes o mesmo partido abriga indivíduos de perspectivas políticas bem diferentes", observa Mainwaring (1999:160-161, tradução dos autores).

3. "Entidade estatal, político-administrativa, com personalidade jurídica, governo próprio e competência normativa" (Meirelles, 1993:116 apud Neves, 2000:18).

4. Artigos I, 29-31, 156, 158 e 159 da Constituição Federal de 1988.

5. Transferências da União por meio do Fundo de Participação dos Municípios - FPM e transferências do Estado na forma de cota-parte municipal do Imposto sobre Circulação de Mercadorias e Prestação de Serviços - ICMS.

6. Depois da Lei de Responsabilidade Fiscal, passaram a vigorar limites constitucionais para despesas totais do Legislativo municipal e para a remuneração dos vereadores. Para os gastos totais: $8 \%$ das receitas tributárias e de transferências constitucionais para os municípios até 100 mil habitantes e 7\% para municípios entre 100.001 e 300 mil habitantes. Já a remuneração dos vereadores corresponderá a $40 \%$ do que é pago aos deputados estaduais nos municípios entre 50.001 e 100 mil habitantes; e a 50\% naqueles entre 100.001 e 300 mil habitantes.

7. A Lei Orgânica Municipal, votada pelo Legislativo Municipal, não fica sujeita a veto ou à sanção do prefeito.

8. O mesmo vale para os pleitos para governador, deputado estadual e deputado federal.

9. A regra que impõe a verticalização constitui uma tentativa de reduzir os problemas de coordenação.

10. Nas cidades com mais de 1 milhão de habitantes, a estrutura municipal se subdividia em distritos.

11. "No período 1946-1964, algumas organizações partidárias com abrangência nacional eram, mais precisamente, uma federação de organizações de base estadual" (Mainwaring, 1999:157, tradução dos autores).

12. As votações do PP e do PPR foram agregadas nas eleições de 1994 e comparadas com as votações do PPB nos demais anos do painel.

13. Existem discrepâncias importantes entre o Tribunal Superior Eleitoral - TSE e o Instituto Brasileiro de Geografia e Estatística - IBGE quanto ao número de municípios do país. O TSE só reconhece os municípios em que o prefeito já foi efetivamente nomeado ou eleito e empossado; o IBGE, o município a partir do decreto de sua criação.

14. A causalidade é entendida aqui no sentido de Granger. Gujarati (2000:627) apresenta a seguinte definição para a causalidade de Granger: "Como o futuro não pode prever o passado, se a variável X causa (no sentido de Granger) a variável Y, então mudanças em $X$ devem preceder mudanças em Y. Portanto, em uma regressão de $Y$ sobre outras variáveis (incluindo seus próprios valores passados), se incluirmos os valores passados ou defasados de $\mathrm{X}$ e isso melhorar significativamente a previsão de $\mathrm{Y}$, podemos então dizer que X causa (no sentido de Granger) Y". 
15. Seguimos Lavareda, que atribuiu às eleições para governador o papel de elemento articulador do sistema: "Esse pleito que de certa forma estruturava em cada estado o desenho das demais competições, inclusive proporcionais" (1991:129).

16. Todas as nossas estimativas foram obtidas com a utilização do procedimento de regressão com variáveis instrumentais do software Stata 8.0. Os resultados dos testes de avaliação para violação da hipótese de homoscedasticidade (Cook-Weisberg) não foram satisfatórios; por isso, optamos por utilizar estimadores robustos da variância (Huber-White). Uma vez que os casos do painel são município/partido, especificamos que as observações são independentes entre municípios, mas que não necessariamente para o mesmo município que aparece mais de uma vez com as proporções de votos de diferentes partidos. Portanto, utilizamos o controle de cluster por município.

17. Modelos de regressão Tobit permitem lidar com amostras em que as informações da variável dependente são limitadas por algum problema de mensuração. Long (1997:188) apresenta uma lista de exemplos de regressão Tobit para variáveis limitadas em estudos de economia e sociologia.

18. A categoria de referência na análise são os municípios com mais de 200 mil habitantes; portanto, essa dummy não foi incluída nas equações especificadas.

19. Nas estimativas por Tobit, a primeira equação foi estimada substituindo-se $\beta_{2} \operatorname{gov}_{(t)}$ por $\beta_{2} \operatorname{gôv}(t)$, estimado pela equação dois do modelo.

20. Nas estimativas por Tobit, a primeira equação foi estimada substituindo-se $\beta_{2} \operatorname{gov}(t)$ por $\beta_{2}$ gôv(t), estimado pela equação dois do modelo.

21. Nas estimativas por Tobit, a primeira equação foi estimada substituindo-se $\beta_{2}$ $\operatorname{pref}_{(t-1)}$ por $\beta_{2} \operatorname{prêf}_{(t-1)}$, estimado pela equação dois do modelo.

22. Nas estimativas por Tobit, a primeira equação foi estimada substituindo-se $\beta_{1} \operatorname{pref}_{(t)}$ por $\beta_{1} \operatorname{prêf}_{(t)}$, estimado pela equação dois do modelo.

23. Esse procedimento - considerar apenas a votação do partido que encabeçava a coligação e imputar zero à votação dos demais partidos da coligação - foi seguido em todas as eleições com as quais trabalhamos.

24. A hipótese nula estabelece que não existe articulação entre os subsistemas partidários local, estadual e nacional.

25. Uma variável dependente $y^{*}$ é latente quando $q \leq y^{*} \leq k$, sendo $q$ e $k$ os limites do intervalo no qual a variável pode ser observada.

26. O limite superior de 0,8 (ou $80 \%$ ) corresponde a um limite escolhido arbitrariamente, a partir do qual consideramos que podem existir problemas com as informações.

27. A dummy para cidades com mais de 200 mil habitantes não foi incluída nas equações e serve, portanto, de base para a comparação com as demais. Não interessa na presente análise oferecer uma interpretação substantiva para o coeficiente estimado para as dummies, o qual indica a diferença entre as médias da variável dependente em uma determinada classe de tamanho de município com relação aos municípios com mais de 200 mil habitantes (Kennedy, 1992:220). 


\section{REFERÊNCIAS BIBLIOGRÁFICAS}

ABRUCIO, Fernando. (1994), “Os Barões da Federação”. Lua Nova, no 33, pp. 165-183. . (1998), Os Barões da Federação. Os Governadores e a Redemocratização Brasileira. São Paulo, Hucitec/USP. e COSTA, Valeriano. (1998), Reforma do Estado e o Contexto Federativo Brasileiro. São Paulo, Fundação Konrad Adenauer Stiftung.

ABRUCIO, Fernando e SAMUELS, David. (1997), “A Nova Política dos Governadores". Lua Nova, nos 40-41, pp. 137-166.

COX, Gary W. (1997), Making Votes Count. Strategic Coordination in the World's Electoral Systems. Cambridge, Cambridge University Press.

DUVERGER, Maurice. (1954), Les Partis Politiques. Paris, Collin.

(1986), "Duverger's Law: Forty Years Later", in B. Grofman e A. Lijphart (eds.), Electoral Laws and their Political Consequences. New York, Agathon Press.

GROFMAN, Bernard e LIJPHART, Arend (eds.). (1986), Electoral Laws and their Political Consequences. New York, Agathon Press.

GUJARATI, Damodar N. (2000), Econometria Básica. São Paulo, Pearson Education do Brasil.

KENNEDY, Peter. (1992), A Guide to Econometrics (3a ed.). Cambridge, The MIT Press.

LAMOUNIER, Bolívar e MENEGUELLO, Rachel. (1986), Partidos Políticos e Consolidação Democrática. O Caso Brasileiro. São Paulo, Brasiliense.

LAVAREDA, Antonio. (1991), A Democracia nas Urnas. O Processo Partidário-Eleitoral Brasileiro. Rio de Janeiro, Iuperj/Rio Fundo.

LIMA JUNIOR, Olavo Brasil de. (1983), Os Partidos Políticos Brasileiros. A Experiência Federal e Regional (1945-64). Rio de Janeiro, Graal.

(1997), Instituições Políticas Democráticas. O Segredo da Legitimidade. Rio de Janeiro, Jorge Zahar.

LONG, J. Scott. (1997), Regression Models for Categorical and Limited Dependent Variables (Advanced Quantitative Techniques in the Social Sciences Series). California, Sage, vol. 7.

MAINWARING, Scott P. (1999), Rethinking Party Systems in the Third Wave of Democratization. The Case of Brazil. Stanford, Stanford University Press.

MEIRELLES, Hely Lopes. (1993), Direito Municipal Brasileiro (6a ed.). São Paulo, Malheiros.

NEVES, Gleisi Heisler. (2000), “O Município no Brasil: Marco de Referência e Principais Desafios”. Cadernos Adenauer, no 4, Fundação Konrad Adenauer.

RAE, Douglas. (1971), The Political Consequences of Electoral Laws. New Haven, Yale University Press.

ROCHA, Adriana de Lacerda. (2001), Autonomia Legislativa Municipal no Direito Brasileiro e Estrangeiro. Rio de Janeiro, Lumens Juris. 
SAMUELS, David J. (1998), Careerism and Its Consequences. Federalism, Elections, and Policy Making in Brazil. San Diego, University of California.

SANTOS, Wanderley Guilherme dos. (2001), "A Democracia e seu Futuro no Brasil”, in J. P. dos R. Velloso (org.), Como Vão o Desenvolvimento e a Democracia no Brasil? Rio de Janeiro, José Olympio, pp. 231-250.

SARTORI, Giovanni. (1982), Parties and Party Systems. A Framework for Analyses. Cambridge, Cambridge University Press.

. (1986), “The Influence of Electoral Systems: Faulty Laws or Faulty Methods?", in B. Grofman e A. Lijphart (eds.), Electoral Laws and Their Political Consequences. New York, Agathon Press.

SHUGART, Mattew S. e CAREY, John M. (1992), Presidents and Assemblies. Constitutional Design and Electoral Dynamics. Cambridge, Cambridge University Press.

SOARES, Gláucio Ary Dillon. (1973), Sociedade e Política no Brasil: Desenvolvimento, Classe e Política durante a Segunda República. São Paulo, Difel.

SOUZA, Celina. (2003), “Federalismo e Conflitos Distributivos: Disputa dos Estados por Recursos Orçamentários Federais”. DADOS, vol. 46, no 2, pp. 345-384.

SOUZA, Maria do Carmo Campello de. (1976), Estado e Partidos Políticos no Brasil (1930/1964). São Paulo, Alfa-Ômega.

\section{LISTA DE SIGLAS}

PDT - Partido Democrático Trabalhista

PFL - Partido da Frente Liberal

PMDB - Partido do Movimento Democrático Brasileiro

PP - Partido Progressista

PPB - Partido Progressista Brasileiro

PPR - Partido Progressista Renovador

PT - Partido dos Trabalhadores

PTB - Partido Trabalhista Brasileiro

PSDB - Partido da Social Democracia Brasileira 


\section{ANEXO}

Tabela 1

Estatísticas Descritivas das Variáveis Incluídas no Modelo (proporções de votos dos partidos nos municípios), segundo o Ano e o Tipo de Eleição

\begin{tabular}{|c|c|c|c|c|c|c|c|c|c|c|}
\hline \multicolumn{7}{|c|}{ Sistema Nacional e Subsistemas Estaduais } & \multicolumn{4}{|c|}{ Subsistemas Locais } \\
\hline Partido & Ano & $\mathbf{N}$ & $\begin{array}{l}\text { Presi- } \\
\text { dente }\end{array}$ & $\begin{array}{c}\text { Gover- } \\
\text { nador }\end{array}$ & \begin{tabular}{|c} 
Deputado \\
Federal
\end{tabular} & \begin{tabular}{|c} 
Deputado \\
Estadual
\end{tabular} & Ano & $\mathbf{N}$ & Prefeito & Vereador \\
\hline & & & Média & Média & Média & Média & & & Média & Média \\
\hline PDT & 1998 & 5.511 & 0,00 & 0,05 & 0,04 & 0,06 & 2000 & 5.513 & 0,06 & 0,06 \\
\hline PFL & & 5.511 & 0,00 & 0,20 & 0,23 & 0,18 & & 5.513 & 0,18 & 0,16 \\
\hline PMDB & & 5.511 & 0,00 & 0,32 & 0,22 & 0,19 & & 5.513 & 0,22 & 0,19 \\
\hline РPB & & 5.511 & 0,00 & 0,08 & 0,12 & 0,12 & & 5.513 & 0,11 & 0,12 \\
\hline PSDB & & 5.511 & 0,60 & 0,19 & 0,18 & 0,15 & & 5.513 & 0,16 & 0,14 \\
\hline PT & & 5.511 & 0,25 & 0,09 & 0,07 & 0,06 & & 5.513 & 0,05 & 0,05 \\
\hline РTB & & 5.511 & 0,00 & 0,01 & 0,06 & 0,08 & & 5.513 & 0,08 & 0,08 \\
\hline PDT & 1994 & 5.017 & 0,00 & 0,13 & 0,06 & 0,08 & 1996 & 5.404 & 0,08 & 0,08 \\
\hline PFL & & 5.017 & 0,00 & 0,11 & 0,18 & 0,16 & & 5.404 & 0,17 & 0,16 \\
\hline PMDB & & 5.017 & 0,07 & 0,23 & 0,26 & 0,23 & & 5.404 & 0,24 & 0,19 \\
\hline РPB & & 5.017 & 0,03 & 0,23 & 0,19 & 0,16 & & 5.404 & 0,12 & 0,12 \\
\hline PSDB & & 5.017 & 0,61 & 0,15 & 0,11 & 0,09 & & 5.404 & 0,16 & 0,14 \\
\hline PT & & 5.017 & 0,21 & 0,07 & 0,07 & 0,06 & & 5.404 & 0,03 & 0,05 \\
\hline РTB & & 5.017 & 0,00 & 0,01 & 0,06 & 0,08 & & 5.404 & 0,07 & 0,07 \\
\hline
\end{tabular}

Elaboração dos autores.

Tabela 2

Matriz de Correlação Parcial das Variáveis Utilizadas

\begin{tabular}{l|rrrrrrrrr|r|}
\cline { 2 - 12 } & govp98 & goup94 & prefp00 & prefp96 & presp98 & dfp94 & dfp98 depest98 depest94 & verp96 \\
\hline goup98 & 1 & & & & & & & & & \\
goup94 & 0,357 & 1 & & & & & & & & \\
prefp00 & 0,309 & 0,187 & 1 & & & & & & & \\
prefp96 & 0,288 & 0,270 & 0,439 & 1 & & & & & & \\
presp98 & 0,121 & $-0,001$ & 0,048 & 0,011 & 1 & & & & & \\
dfp94 & 0,356 & 0,429 & 0,273 & 0,343 & $-0,099$ & 1 & & & & \\
dfp98 & 0,516 & 0,337 & 0,359 & 0,357 & 0,090 & 0,505 & 1 & & & \\
depest98 & 0,478 & 0,307 & 0,345 & 0,341 & 0,054 & 0,390 & 0,516 & 1 & & \\
depest94 & 0,303 & 0,390 & 0,260 & 0,338 & $-0,135$ & 0,525 & 0,338 & 0,430 & 1 & \\
verp96 & 0,373 & 0,333 & 0,455 & 0,682 & $-0,024$ & 0,463 & 0,450 & 0,442 & 0,445 & 1 \\
verp00 & 0,372 & 0,238 & 0,711 & 0,494 & 0,027 & 0,356 & 0,452 & 0,444 & 0,337 & 0,641 \\
\hline
\end{tabular}

Elaboração dos autores. 


\section{ABSTRACT \\ Defining the Local Political Arena: Municipal Party Systems in the Brazilian Federation}

This article analyzes the Brazilian political system from the local perspective. Following Cox (1997), we review the problems with electoral coordination that emerge from a given institutional framework. Due to the characteristics of the Brazilian Federal system and its electoral rules, linkage between the three levels of government is not guaranteed a priori, but demands a coordinating effort by the parties' leadership. According to our hypothesis, the parties are capable of coordinating their election strategies at different levels in the party system. Regression models based on two-stage least squares (2SLS) and TOBIT, analyzing a panel of Brazilian municipalities with data from the 1994 and 2000 elections, show that the proportion of votes received by a party in a given election correlates closely with its previous votes in majoritarian elections. Despite institutional incentives, the Brazilian party system shows evidence that it is organized nationally to the extent that it links the competition for votes at the three levels of government (National, State, and Municipal).

Key words: local politics; Brazilian party system

\section{RÉSUMÉ}

Une Définition de l'Arène Politique Locale: Systèmes de Partis Municipaux dans la Fédération Brésilienne

Dans cet article, on examine le système politique du point de vue local. Selon l'exemple de Cox (1997), on considère les problèmes de coordination électorale qui surgissent à partir d'un cadre institutionnel donné. Compte tenu des caractéristiques de la fédération brésilienne et de ses règles électorales, l'articulation entre les trois sphères du gouvernement n'est pas assurée et demande un effort de coordination de la part des leaders des partis. On part de l'hypothèse que les partis sont capables de coordonner leurs stratégies électorales à divers niveaux du système. Les estimations des modèles de régression à deux stades (2SLS) et par TOBIT, prenant pour base un panel de municipalités brésiliennes comprenant les données des élections de 1994 et 2000, montrent que la proportion des votes reçus par un parti lors d'une élection est étroitement liée aux votes reçus précédemment aux élections majoritaires. Malgré les aides institutionnelles, le système brésilien de partis semble organisé nationalement dans la mesure où il articule la compétition électorale aux trois niveaux de gouvernement.

Mots-clé: politique locale; système brésilien de partis 